\title{
Puñales del Bronce de La Mancha
}

\author{
amparo Hernando Grande *
}

Las aportaciones y referencias, que los trabajos de investigación arqueológica y las fuentes bibliográficas nos ofrecen acerca de los materiales metálicos procedentes de la Meseta, durante la Edad del Bronce son tradicionalmente muy numerosas, pero muy pocos los yacimientos excavados y por tanto con contextos y estratigrafias conocidas.

Dentro del marco cultural de la Edad del Bronce, la Meseta presenta una gran heterogeneidad como consecuencia de las diferentes caracteristicas y manifestaciones que esta cultura nos ofrece en la zona Norte, Sur (Submeseta Norte y Submeseta Sur) y Región Centro.

En los últimos tiempos se ha visto muy enriquecido el panorama que presenta este área geográfica de la Meseta durante dicho periodo, gracias a la investigación planificada llevada a cabo especialmente en los trabajos de campo realizados en yacimientos de la Submeseta Sur, Ilenando en gran medida el vacio que tradicionalmente ha venido sufriendo esa gran unidad geográfica que ocupa la zona central de la Peninsula Ibérica y a revalorizar su papel en la Pre y Protohistoria.

En este sentido y como consecuencia de esta investigación planificada se ha podido identificar dentro del ámbito de la Submeseta Sur el complejo cultural denominado Bronce de La Mancha, siendo uno de sus elementos definidores la metalurgia, ya que la caracteristica más relevante de los yacimientos excavados en la zona, sobre todo, de los que se están excavando actualmente, es el conisiderable número de piezas y objetos metálicos que se encuentran en ellos. Debiendo señalar que dentro de este conjunto de piezas metálicas alcanzan un porcentaje importante las armas y dentro de ellas son los puñales y las puntas de flecha los que ofrecen un mayor grado de representatividad.

\footnotetext{
* Departamento de Prehistoria e Historia Antigua, UNED.
} 
Tenemos constancia de la presencia de puñales en los yacimientos de La Peñuela y Dehesa de Caracolares en la provincia de Albacete; en los de la Motilla de Los Palacios, Motilla de Santa Maria del Retamar y cerro de La Encantada en la provincia de Ciudad Real; y por último en la provincia de Cuenca en el del cerro de El Cuco.

Dos son los puñales que respectivamente proceden de La Peñuela y Dehesa de Caracolares, uno de la Motilla de Los Palacios, tres de la Motilla de Santa Maria del Retamar, dieciséis del cerro de La Encantada y uno del cerro del El Cuco.

Son estos yacimientos, junto con otros más, sin olvidar realzar la «personalidad propia» de cada uno de ellos, los que han permitido establecer las bases y definir ese Complejo cultural en que se encuentran insertados como es el Bronce de La Mancha.

\section{ALBACETE}

Del cerro La Peñuela (yacimiento que debe considerarse de tipo Motilla) procede un puñal de cobre, plano y triangular de $13,3 \mathrm{~cm}$ de longitud y $5 \mathrm{~cm}$ de anchura máxima (fig. 1), que presenta dos remaches dispuestos horizontalmente.

\section{Contexto:}

- Metálico: una punta de flecha triangular con pedúnculo y aletas. Lítico: un fragmento de hacha pulimentada. Óseo: una punta de flecha y un punzón. Cerámico: fragmentos de vasos lisos de paredes verticales, troncocónicas y parabólicas, vasos carenados y un candil.

De Dehesa de Caracolares (yacimiento que debe considerarse del mismo tipo que el anterior) procede un puñal de cobre de semejantes caracteristicas, es plano y triangular de $5,8 \mathrm{~cm}$ de longitud y $2,3 \mathrm{~cm}$ de anchura máxima (fig. 2), presenta dos remaches dispuestos horizontalmente.

Contexto:

- Metálico: punta de flecha foliforme y punta de flecha triangular con pedúnculo y aletas. Litico: fragmentos de hachas pulimentadas y un brazal de arquero. Óseo, concha: punzones y conchas perforadas. 
Cerámico: cerámica general lisa, destacando las grandes tinajas, los cuencos y los vasos carenados.

No quisiéramos continuar sin hacer una breve referencia a los trabajos de campo que se están realizando actualmente en El Acequión, este yacimiento ha proporcionado un considerable número de materiales metálicos entre los cuales se encuentran bien representadas las armas, constatándose un puñal de similares características a los tratados.

CIUDAD REAL

De la Motilla de los Palacios conocemos un puñal de cobre, plano y triangular de $11 \mathrm{~cm}$ de longitud y $2 \mathrm{~cm}$ de anchura (fig. 3) con dos remaches dispuestos horizontalmente.

\section{Contexto:}

- Metálico: punta de flecha triangular con pedúnculo y aletas. Litico: piezas dentadas y objetos de piedra pulida. Óseo: punzones y agujas. Cerámico: vasos carenados, vasijas grandes con carena media y decoradas en ocasiones con pequeños mamelones, cuencos de casquete esférico. Cerámica de cocina: ollas y orzas globulares que a veces ofrecen el borde decorado con incisiones o impresiones a punzón. Piezas macizas de arcilla en forma de carrete.

Del cerro de La Encantada proceden dieciséis puñales, siete de estos puñales fueron hallados en el área de habitación, concretamente en el estrato II. El primero es un puñal plano y triangular que mide $11,1 \mathrm{~cm}$ de longitud y $1,7 \mathrm{~cm}$ de anchura máxima (fig. 4), presenta cuatro remaches en disposición paralela. El segundo puñal es igualmente plano y triangular de $9,3 \mathrm{~cm}$ por $2,9 \mathrm{~cm}$ (fig. 5) y presenta un único remache. El tercero es de las mismas características que los anteriores, aunque presenta un ligero bisel marginal, con dos remaches dispuestos horizontalmente, mide $5,8 \mathrm{~cm}$ por $3,7 \mathrm{~cm}$ (fig. 6). El cuarto y quinto son dos puñales planos y triangulares que presentan, respectivamente, dos remaches dispuestos 


$$
\begin{aligned}
& \bar{E} \\
& \mathbb{E}^{-}-\mathbb{1}
\end{aligned}
$$




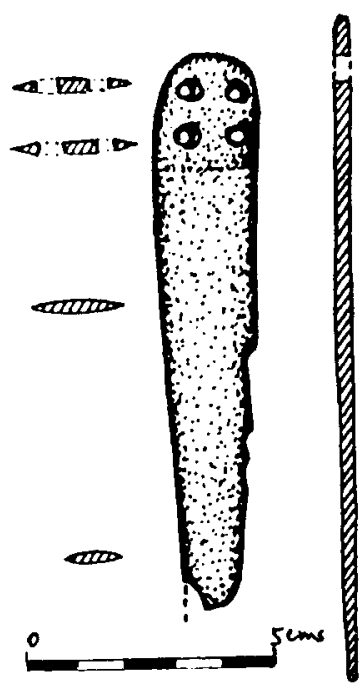

Fig. 4

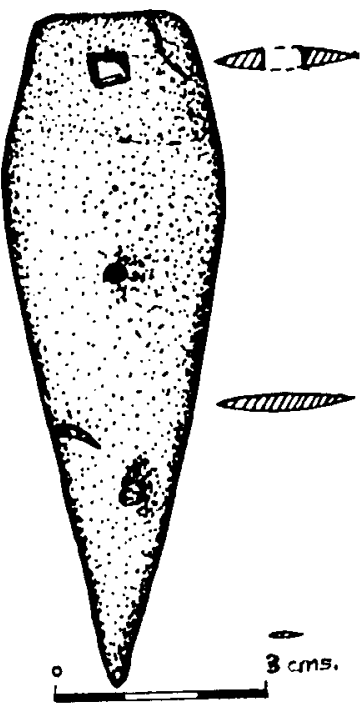

Fig. 5.
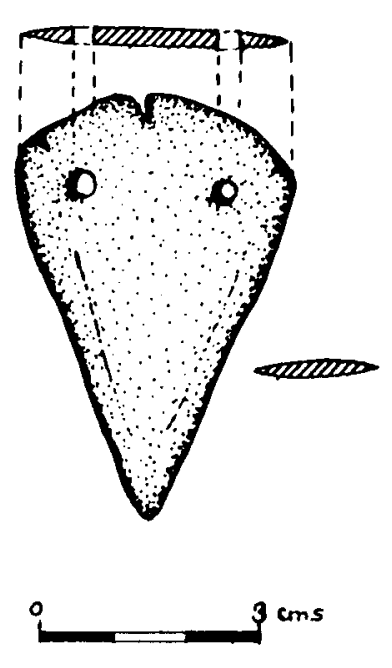

Fig. 6.

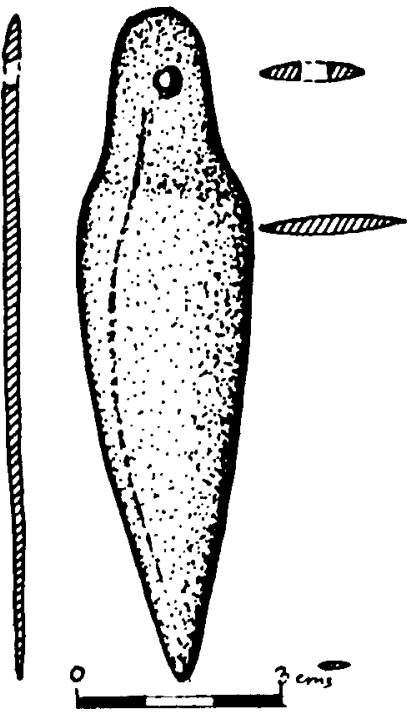

Fig. 9

Fig. 7.

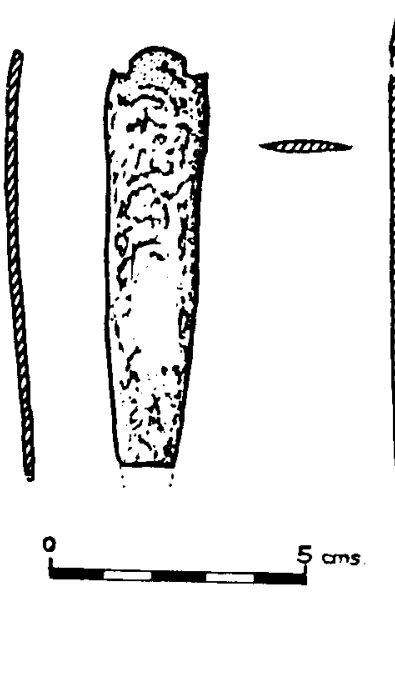

Fig. 8.

Cerro de La Encantada 
Contexto, estrato II:

- Metálico: dos hachas planas trapezoidales, dos puntas de flecha palmela, una punta de flecha foliforme, cinco puntas de flecha triangulares con pedúnculo y aletas, punzones y cinceles. Lítico: denticulados, dientes de hoz, núcleos y lascas, alisadores, machacadores, molederas activas y pasivas, brazales de arquero con dos y cuatro perforaciones, cantos rodados. Óseo: punzones, puntas, botones con perforación en $\mathrm{V}$, colgantes y cuentas de collar. Marfil: rodajas. Cerámico: cuencos hemiesféricos y de casquete esférico, ollas de acusado perfil en $S$, vasos carenados con mamelones en la linea de la carena, vasos queseros o coladores, fichas circulares. Decoración lisa y tipo Dornajos.

Igualmente en el cerro de La Encantada fueron hallados otros ocho puñales, concretamente en el nivel III, dos procedentes del área de habitación y seis del área funeraria del mismo. Uno de los dos puñales del área de habitación presenta características semejantes a los anteriores, ya que es plano y triangular con dos remaches dispuestos horizontalmente, y mide $7,6 \mathrm{~cm}$ por $2 \mathrm{~cm}$ (fig. 11), el otro puñal es igualmente triangular y plano pero en este caso la hoja presenta un marcado bisel marginal, porta tres remaches dispuestos horizontalmente y uno superior, vertical al del centro, mide $20 \mathrm{~cm}$ de longitud (uno de los de mayor longitud procedentes de este yacimiento) por $3,2 \mathrm{~cm}$ de anchura máxima (fig. 12).

Contexto nivel III, área de habitación

- Litico: machacadores, alisadores y cantos rodados. Cerámico: ollas de mediano y gran tamaño, vasos carenados, cuencos hemiesféricos y cuencos más grandes semiesféricos, dos ejemplares de copas argáricas y pesas de telar.

En el área funeraria del nivel III, fueron hallados los seis puñales restantes, el primero es un puñal plano y posiblemente triangular (fragmentado), que presenta dos remaches dispuestos horizontalmente, mide 9,2 $\mathrm{cm}$ por $2,5 \mathrm{~cm}$ (fig. 13).

El segundo puñal es triangular y plano con rebaje marginal a los largo de la hoja, presenta seis remaches dispuestos en cuadrado, sus medidas son $21 \mathrm{~cm}$ de longitud (de los más largos procedentes del yacimiento) por 
$4,5 \mathrm{~cm}$ (fig. 14). Este puñal formaba parte del ajuar de la sepultura 6 , junto a un remaches que podria pertenecer al mismo puñal, un cuenco liso y un diente de hoz. La sepultura estaba formada por una estructura de forma oval, construida por piedras pequeñas trabadas con argamasa y cal. Cubriendo el enterramiento, aparecia gran cantidad de piedras mezcladas con tierra suelta y con otra más compacta, que podrian constituir su cubierta. Esta sepultura contenía un doble enterramiento de inhumación.

El tercer puñal (fragmentado) es plano y posiblemente presentase dos remaches dispuestos horizontalmente, mide $5,1 \mathrm{~cm}$ por $2,4 \mathrm{~cm}$ (fig. 15), se halló formando parte del ajuar de la sepultura 7-1, construida con mampostería de piedras de tamaño medio, siendo su forma rectangular. Esta sepultura, que parece tratarse de una inhumación individual, se encuentra muy alterada y en parte destruida, lo que ha producido la mezcla de materiales. Pero los objetos documentados con seguridad, como ajuar de la tumba son además del puñal, unas cuentas y elementos de collar de piedra, un diente de hoz, un hachita pulimentada, un punzón metálico, una olla y una moledera pasiva.

El cuarto puñal es plano y triangular, presentando ligero bisel marginal en la hoja, con tres remaches dispuestos en triángulo, mide $11,3 \mathrm{~cm}$ por $3,8 \mathrm{~cm}$ (fig. 16), este puñal forma parte del ajuar de la sepultura 7-2, se trata de un enterramiento de inhumación doble y está construida por lajas de piedra de mediano tamaño. El ajuar estaba formado, además del puñal, por dos cuencos uno de ellos con un punzón metálico en su interior.

El quinto puñal es triangular y plano con ligero bisel marginal en su hoja, presenta dos remaches dispuestos horizontalmente, sus medidas son de $12,9 \mathrm{~cm}$ por $2,7 \mathrm{~cm}$ (fig. 17). Procede de la sepultura 17, que corresponde a un doble enterramiento de inhumación, ésta nos ofrece una planta sensiblemente elipsoidal revestida de mampostería a base de grandes piedras. El ajuar constaba, además de este puñal, de un cuenco de pequeñas dimensiones y un alisador.

El sexto y último puñal, procedente del área funeraria del nivel III del yacimiento, es plano y triangular con dos remaches dispuestos en horizontal, tiene una longitud de $4,65 \mathrm{~cm}$ y una anchura máxima de $2,2 \mathrm{~cm}$ (fig. 18). Forma parte del ajuar de la sepultura 43, que corresponde a un enterramiento doble de inhumación en grieta natural. El ajuar constaba además de un punzón metálico y un vaso carenado.

El último puñal, procedente del cerro de La Encantada, es plano y triangular con ligero bisel marginal, presenta tres remaches dispuestos en triángulo, midiendo $6,6 \mathrm{~cm}$ por $2,4 \mathrm{~cm}$ (fig. 19), fue hallado en el estrato IV. Se trata de un estrato de derrumbe, aunque pese a ello, aparece en 


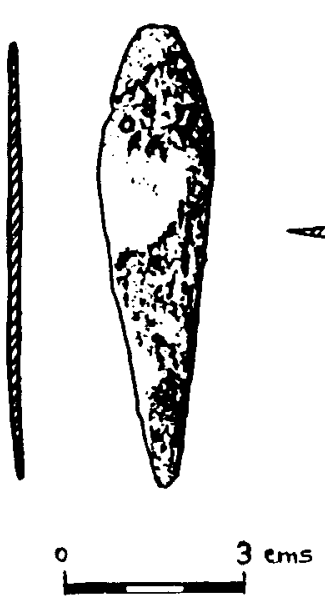

Fig. 10.

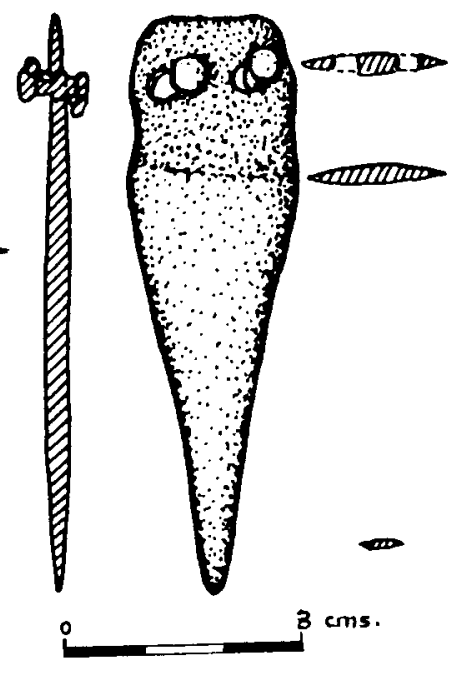

Fig. 11.

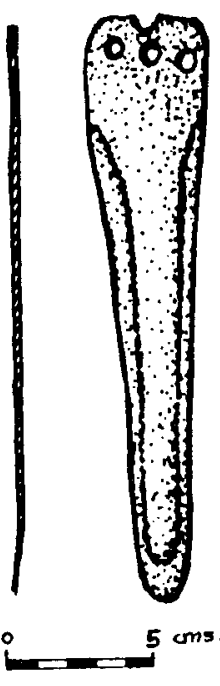

Fig. 12

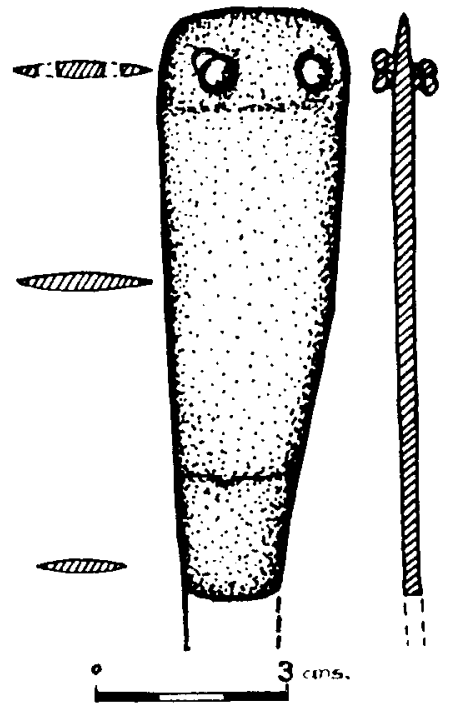

Fig. 13.

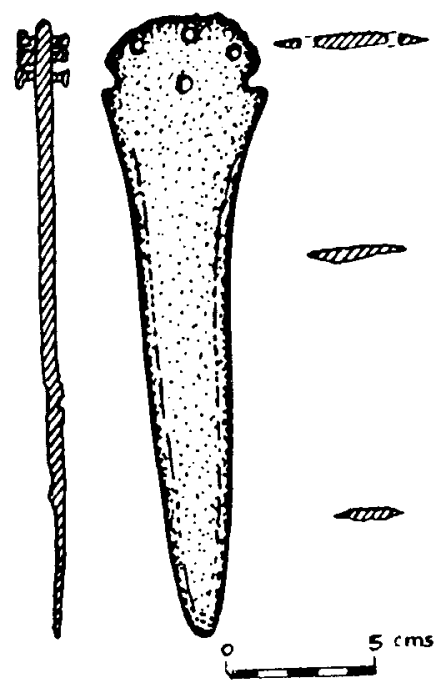

Fig. 14

Cerro de La Encantada 


\section{Puñales del Bronce de La Mancha}

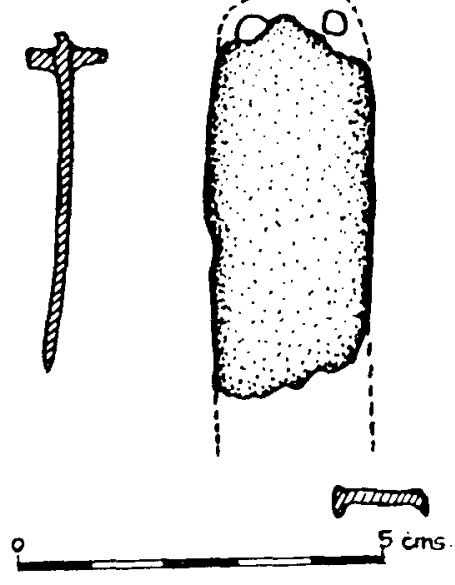

Fig. 15

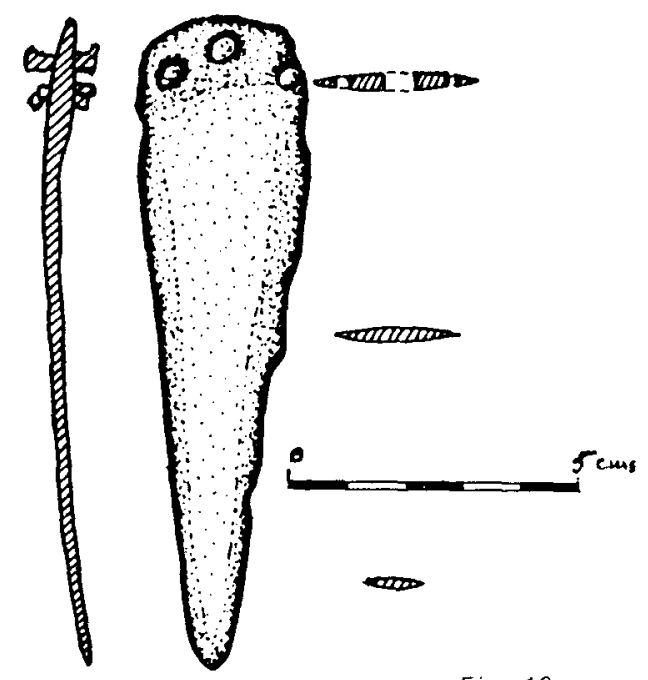

Fig. 16

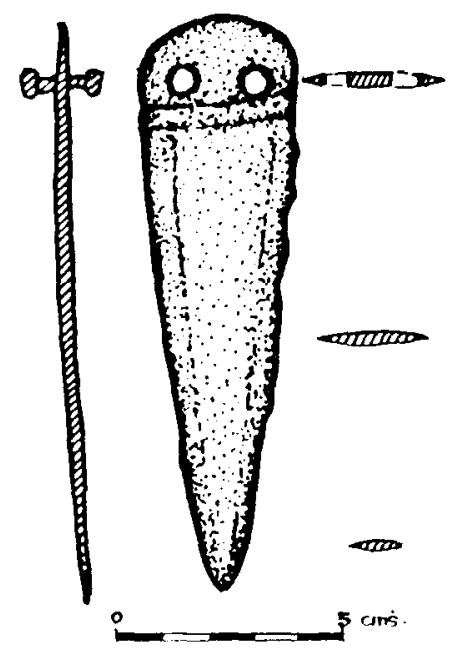

Fig. 17.

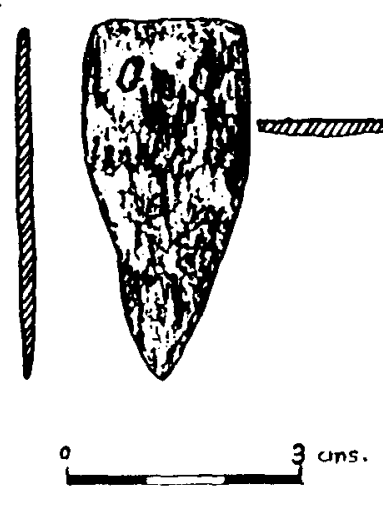

Fig. 18

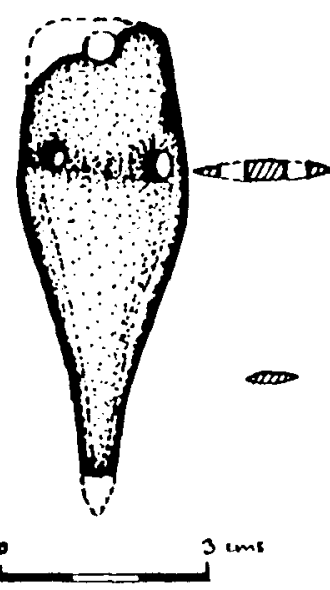

Fig. 19

Cerro de La Encantada 
él abundante material. Destacan los cuencos semiesféricos con impresiones o incisiones en los bordes, cazuelas, grandes ollas de perfil en $\mathrm{S}$, vasos carenados, fichas, algún punzón de hueso, uno de metal y escaso silex.

Todos los puñales procedentes de este yacimiento están fabricados en cobre.

De la Motilla de Santa María del Retamar proceden tres puñales de cobre, el primero es un puñal plano y triangular que presenta dos remaches dispuestos horizontalmente, mide $4,9 \mathrm{~cm}$ de longitud por $2,6 \mathrm{~cm}$ de anchura máxima (fig. 20). El segundo es de similares características al anterior, mide $4,4 \mathrm{~cm}$ por $2,5 \mathrm{~cm}$ (fig. 21). El último puñal es plano y triangular y ofrece, en este caso, tres remaches dispuestos en triángulo, sus medidas son de $15,5 \mathrm{~cm}$ por $4,8 \mathrm{~cm}$ (fig. 22).

\section{Contexto:}

- Metálico: diez puntas de flecha triangulares con pedúnculo y aletas, una punta de flecha foliforme y varios punzones. Lítico: pequeñas piezas denticuladas, algunos fragmentos de hojas, lascas y núcleos. "Cantos trabajados" en cuarcita. En piedra pulimentada abundan las molederas y los machacadores, asi como los afiladores, alisadores y bruñidores. Las hachas pulimentadas son escasas. Brazales de arquero, un colgante rectangular, un collar de cuentas discoidales, fragmento de una pulsera de caliza, un botón de perforación en $V$ y objetos como las denominadas "fichas". Óseo, concha: punzones de varios tamaños y tipos, algunas agujas y espátulas, una punta de flecha y una pieza rectangular de cuatro orificios, conocidas como «separadores de collar». En concha destacan las perforadas. Marfil: pequeño botón piramidal de perforación en V. Cerámico: los materiales cerámicos son los más abundantes en el yacimiento, siendo de buena calidad y de distintas variedades, sobre todo de cuencos y ollas, con impresiones en los bordes y algunos con asas, vasos ovoides con o sin mamelones y vasos carenados algunos con mamelones en la carena. Entre los objetos cerámicos destacan los vasos coladores, cucharas y pesas de telar, asi como las denominadas «fichas».

\section{CUENCA}

Del cerro de El Cuco procede un puñal de cobre fragmentado en la zona mesial, plano y con dos remaches dispuestos horizontalmente, mide $3 \mathrm{~cm}$ de longitud y $2 \mathrm{~cm}$ de anchura máxima que fue hallado en superficie (fig. 23). 


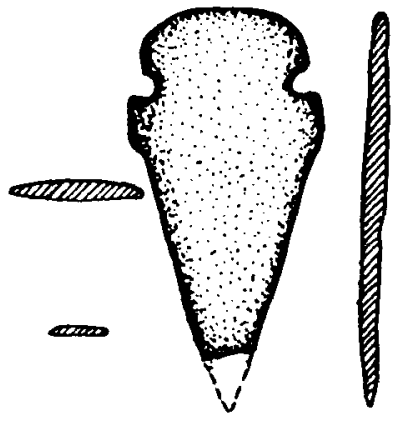

o

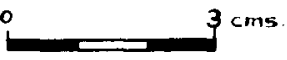

Fig. 20.
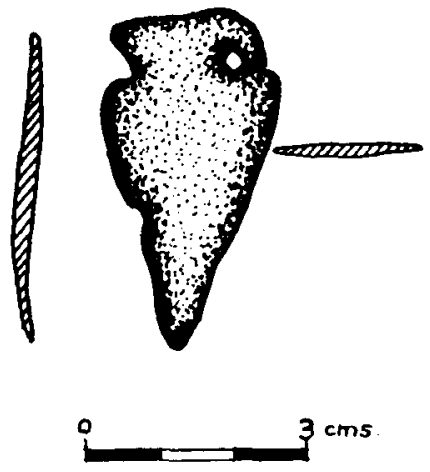

Fig. 21.

Motilla de Santa Maria del Retamar

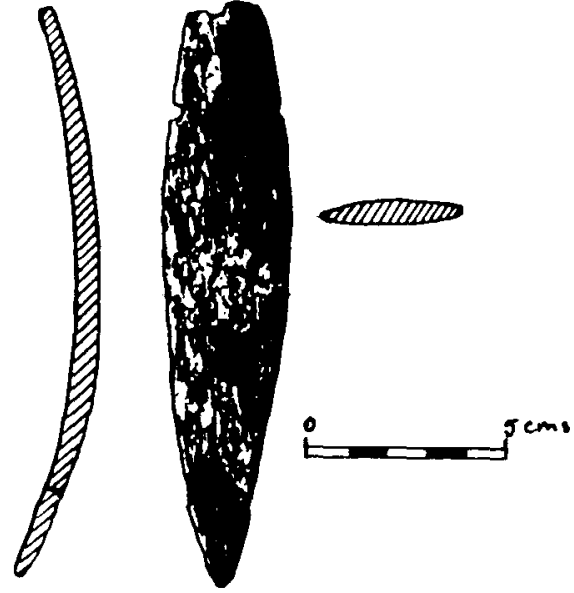

Fig. 22.

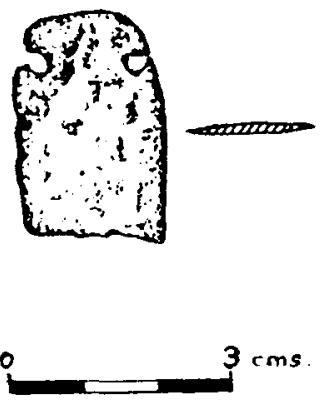

Fig. 23

Motilla de Santa Maria del Retamar

Cerro de El Cuco.

Desde el punto de vista morfológico, puede observarse que los puñales tratados presentan caracteristicas semejantes, perteneciendo todos al tipo de puñal de remaches plano y triangular, con alguna variación respecto al número de remaches y la disposición de los mismos. Tenemos 
que hacer una excepción con dos puñales procedentes del cerro de La Encantada, en los cuales aparece la empuñadura mixta o combinación de remaches y lengüeta, en ambos casos la lengüeta se presenta indiferenciada de la hoja, es decir el estrechamiento simétrico de los dos bordes del extremo más ancho de la hoja, que origina la lengüeta, está poco pronunciado.

Por otra parte, los puñales que nos ocupan están perfectamente constatados en yacimientos tipo habitats o asentamientos en cerros y motillas, relacionándose en estos casos y respectivamente con el resto de los materiales citados anteriormente, procedentes de cada yacimiento, que conjuntamente conformarian sus contextos. Si bien creemos que es interesante resaltar la presencia de estos puñales formando parte de ajuares funerarios de algunas sepulturas del cerro de La Encantada, no teniendo ya constancia, hasta ahora de caso similar en otros yacimientos de la Meseta en general ni de la Submeseta Sur en particular, durante este momento cultural.

Es evidente que del conjunto de materiales metálicos presentes en estos yacimientos de La Mancha, son, sobre todo, las armas (puntas de flecha foliformes, triangulares con pedúnculo y aletas, puñales de remaches, etc.), las que nos ofrecen, en primer lugar una amplia visión del aspecto cultural, cronológico y geográfico del Bronce Medio o Pleno en esta zona, en segundo lugar, son ellas, también, las que nos hablan de las relaciones con otros complejos culturales como el Bronce Valenciano y el Argar, y por último las armasn han sido uno de los factores básicos para definir la "personalidad propia" del complejo cultural al que pertenecen como es el Bronce de La Mancha.

\section{RESUMEN}

Uno de los elementos definidores del Bronce de La Mancha es el considerable número de materiales metálicos hallados en los yacimientos de la zona, siendo, entre ellos, las armas las que alcanzan un indice importante de representatividad, sobre todo las puntas de flecha y los puñales. Son en estos últimos donde centramos nuestra atención, refiriéndonos, en primer lugar a sus características morfológicas, en segundo lugar al tipo 
de yacimiento de donde proceden y en último lugar, al conjunto de materiales con los cuales se presentan asociados.

\section{ABSTRACT}

One of the elements which define the Bronze Age in La Mancha is the substantial amount of metallic materials found in the area sites and, amongs them, the armament reaches the most important representation, especially the arrow-heads and the daggers. These last are the ones we will focus on. First, we will refer to their morphologyc characteristics, second, to the kind of site where they were found and, finally to the ensemble of materials with which they appear associated.

\section{BIBLIOGRAFIA}

Colmenarejo, R. et alii (1988): "La Motilla de Santa Maria del Retamar (Argamasilla de Alba, Ciudad Real)», Oretum, n. ${ }^{\circ}$ III. Ciudad Real, págs. 80-108.

Fernandez Miranda, M. el alii (1988): "Caracterización de la Edad del Bronce en La Mancha. Algunas proposiciones para su estudio", Espacio, Tiempo y Forma, serie I. Prehistoria, t. I. Madrid, págs. 293-310.

NÁjera, T. y Molina, F. (1977): "La Edad del Bronce en La Mancha. Excavaciones en las Motillas del Azuer y Los Palacios", Cuadernos de Prehistoria de la Universidad de Granada, n. ${ }^{\circ}$ II. Granada, págs. 251 y ss.

Nieto, G, y S. Meseguer, J. (1980): "El cerro de La Encantada. Granátula de Calatrava (Ciudad Real)". Excavaciones Arqueológicas en España, n. 113. Madrid.

Romero, H. y S. Meseguer, J. (1988): “El cerro de El Cuco o de La Coronilla. Un yacimiento del área suroriental de La Mancha", I Congreso de Historia de Castilla-La Mancha (Toledo), t. II, págs. 335-342.

SÁNCHEZ JIMENEZ, J. (1948): "La Cultura Argárica en la provincia de Albacete. Notas para su estudio". Actas y Memorias de la Sociedad Española de Antropologia, Etnologia y Pre-

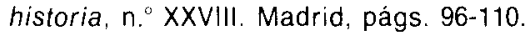

